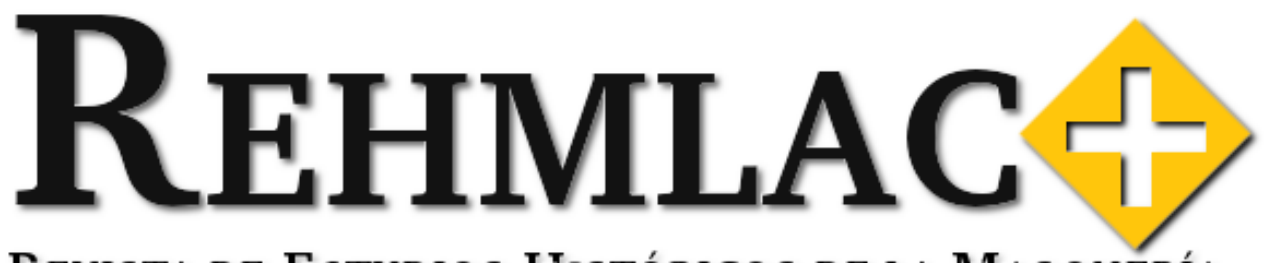

Revista de Estudios Históricos de la Masonería L.ATINoAmerica y Caribeña | I S S N 1659-4223

Volumen 10, número 1, mayo -noviembre 2018

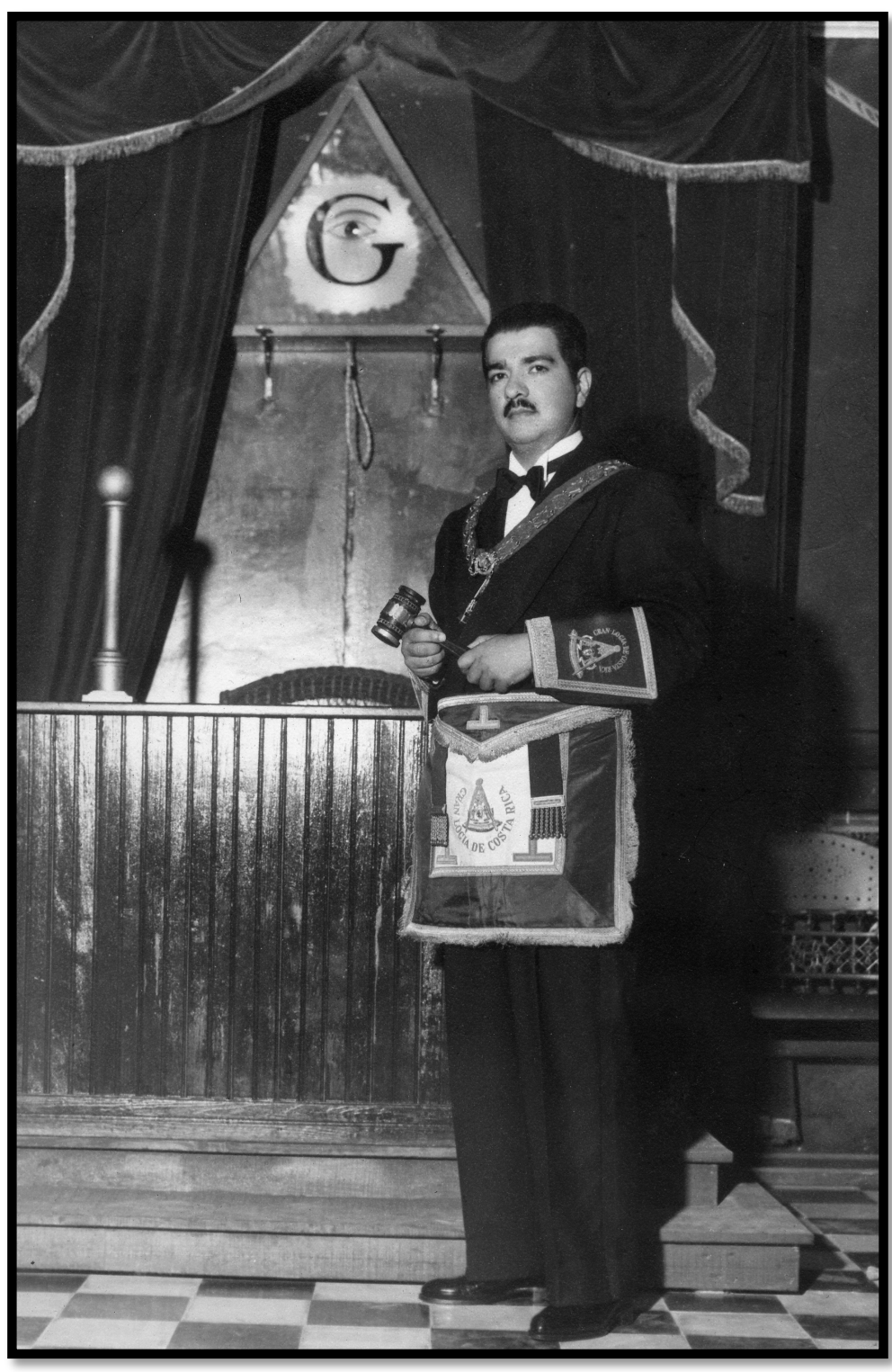

Dirección Web: http://rehmlac.ucr.ac.cr/

Correo electrónico: rehmlac@ucr.ac.cr

Universidad de Costa Rica 
Portada: Rafael Obregón Loría (1911-2000), tal vez el masón más importante de la Costa Rica del siglo XX, también sobresalió como uno de los más notables historiadores y humanistas de su época. Sus investigaciones se encuentran entre la historia decimonónica del país, los estudios sobre la masonería y la campaña nacional contra los filibusteros (1856-1857). Masón por casi 40 años, ocupó el cargo de gran maestro de la Gran Logia de Costa Rica, así como el de venerable maestro de la logia Hermes no. 7 en seis ocasiones, además, organizó en esa institución el museo que actualmente lleva su nombre.

Fuente: Gran Logia de Costa Rica, Museo Masónico Rafael Obregón Loría, "Fotografías Hermandad Rafael Obregón Loría”, \# 29. 


\section{Equipo REHMLAC+}

Consejo Científico

Miguel Guzmán-Stein (Universidad de Costa Rica, Costa Rica)

José Antonio Ferrer Benimeli (Universidad de Zaragoza, España)

Margaret Jacob (Universidad de California Los Ángeles, Estados Unidos)

Eduardo Torres Cuevas (Universidad de La Habana, Cuba)

María Eugenia Vázquez Semadeni (Universidad de California Los Ángeles, Estados Unidos)

Éric Saunier (Universidad de Havre, Francia)

Andreas Önnerfors (Universidad de Lunds, Suecia)

Samuel Sánchez Gálvez (Universidad Estatal de Ecuador)

Roberto Valdés Valle (Universidad Evangélica de El Salvador)

Céline Sala (Universidad de Perpiñán, Francia)

Dominique Soucy (Universidad de Franche-Comté, Francia)

Guillermo de los Reyes Heredia (Universidad de Houston, Estados Unidos)

Dévrig Mollés (Universidad de Estrasburgo, Francia)

Felipe Santiago del Solar (Universidad París Diderot-París 7, Francia)

Michel Goulart da Silva (Universidad del Estado de Santa Catarina, Brasil)

Esteban Sánchez Solano (Universidad de Costa Rica, Costa Rica)

Jeffrey Tyssens (Universidad Libre de Bruselas, Bélgica)

Aldo Alessandro Mola (Universidad de Milán, Italia)

Juan Pablo Bubello (Universidad de Buenos Aires, Argentina)

Marco Flores Zavala (Universidad Autónoma de Zacatecas, México)

Marco Novarino (Universidad de Turín, Italia)

Correctores de estilo

Sylvia Hottinger (Universidad Carlos III de Madrid, España)

Kyle Jackson (University of California Los Angeles, Estados Unidos)

Diseñador y administrador $W e b$

Luis Martín Valverde Alfaro (Universidad de Costa Rica)

Redes y prensa

Julio Martínez García (Universidad de Salamanca, España)

Editor

Yván Pozuelo Andrés (IES Universidad Laboral de Gijón, España)

Director

Ricardo Martínez Esquivel (Universidad de Costa Rica) 


\section{Definición de la Revista}

La REHMLAC+ es una revista electrónica, multidisciplinaria y semestral, que nace para la difusión científica en torno a la historia global de las masonerías. Publica artículos de investigación, entrevistas (en particular a experiencias investigativas en tesis), reseñas de actividades académicas, reseñas de publicaciones y semblanzas. Esta revista se edita en la Universidad de Costa Rica y se dirige a toda interesada o interesado en la temática, desde miembros de la comunidad académica hasta el público en general.

La REHMLAC+ es parte del Programa Latinoamericano de Estudios Históricos de las Masonerías y los Movimientos Asociativos, inscrito en la Sección de Historia de la Cultura de la Escuela de Estudios Generales de la Universidad de Costa Rica. Este programa, a su vez, forma parte de una red académica, que incluye:

1. Casa de Altos Estudios Don Fernando Ortiz, Universidad de La Habana, Cuba.

2. Centro de Estudios Históricos de la Masonería Española (CEHME), Universidad de Zaragoza, España.

3. Freemasonry and Civil Society Program, University of California, Los Angeles (UCLA), Estados Unidos.

4. Groupe de Recherche Interdisciplinaire Franc-Maçonnerie, Vrije Universiteit Brussel, Bélgica.

5. Centro de Estudios sobre Esoterismo Occidental / UNASUR, Argentina.

6. Programa Modular en Órdenes, Corporaciones, Academias y Sociedades: Historia de los Movimientos Asociativos, Universidad Nacional de Educación a Distancia (UNED), España.

7. Centro di Ricerche Storiche sulla Libera-Muratoria (CRSL-M), Turín, Italia.

8. Programa de Maestría y Doctorado en Historia de la Universidad Autónoma de Zacatecas, México.

La REHMLAC+ es una publicación de acceso abierto o libre a texto completo ("Open Access"), editada en San José, Costa Rica y dirigida a toda interesada o interesado en la temática, desde miembros de la comunidad académica hasta el público en general. Por lo tanto, sus contenidos están protegidos por legislaciones como la Declaración de Berlín (2001), comparte iniciativas como la Budapest Open Access Initiative (BOAI), tiene una licencia Creative Commons de tipo "Atribución - No Comercial - Compartir Igual” 4.0 Internacional y aplica el protocolo OAI_PMH del "Open Archives Initiative”. 
La REHMLAC+ se encuentra indizada o resumida en SciELO, Red ALyC, DOAJ, Latindex-Directorio, UCRIndex, ERIH PLUS, Dialnet, Actualidad Iberoamericana, REDIB, MIAR, BASE, Sherpa/Romeo, REDIAL e Hispana.

Los derechos de edición y publicación son de la revista y la propiedad intelectual de los artículos pertenece a los autores. Los artículos publicados en la revista podrán ser utilizados libremente para propósitos educativos y científicos, siempre y cuando se realice la referencia bibliográfica correcta. El uso comercial de los artículos publicados en esta revista queda penado por las disposiciones internacionales. 


\section{Presentación}

\section{Prácticas asociativas y modernidad}

La finalización de las celebraciones por los 300 años de la masonería moderna, ocurridas en el mundo entero a lo largo del año 2017, no ha desanimado a los historiadores para continuar ahondando sobre los orígenes históricos de la masonería y el estudio de su desarrollo. En ese sentido, la polémica sobre lo ocurrido en Londres que surgió el pasado año, continuó en el 2018 a través de la celebración del Simposio "1717 and All That", celebrado en Londres el 15 de febrero, al amparo de la Logia Quatuor Coronati no. 2076. En ese evento Andrew Prescott y Susan Sommers expusieron sus argumentaciones para asegurar que la primera Gran Logia de Londres y Westmister fue fundada en 1721 y no en 1717, en tanto que John Hamill y Ric Berman mantienen como cierta la fecha de 1717. Este encuentro incluyó a otros nueve expositores que debatieron sobre el tema, como Cécile Révauger, John Belton, Steve Smith y John Wade, así como dejó abierto el tema a un debate que promete interesantes contribuciones a la historiografía masónica.

Del otro lado del Atlántico, junto al Pacífico, el Programa de Masonería y Sociedad Civil de la Universidad de California en Los Ángeles (UCLA Freemasonry and Civil Society Program), celebró el 7 de abril la 2018 la 7th. UCLA Internacional Conference, bajo el tema "Secular Enlightenment-Balancing Faith and Masonic Virtues", que daba continuidad a las anteriores Conferencias de la UCLA. Asimismo, se realizó un merecido homenaje a la doctora Margaret Jacob, profesora distinguida de la UCLA y directora del programa citado, quien al final de este semestre se acogerá a la jubilación. Los méritos y las contribuciones de la Profesora la han convertido en una de las más prestigiosas y respetadas especialistas en la historia de la masonería, en teoría política, en historia de la ciencia y en el desarrollo de los pueblos y las ideas. A este homenaje se unió la Gran Logia de California con sus más altas autoridades y un gran número de miembros participantes.

Esta conferencia reunió a un conjunto de especialistas de Europa y América, que trataron temas sobre la masonería y la ilustración en el mundo durante el siglo XVIII e inicios del XIX: José Antonio Ferrer Benimeli de la Universidad de Zaragoza, Jessica Harland-Jacobs de la Universidad de Florida, Remzi Sanver de la Universidad de Istanbul Bilgi, PierreYves Beaurepaire de la Universidad de Niza, Reinhard Markner de la Universidad de Innsbruck, Susan Mitchell Sommers de Saint Vincent College, Pennsylvania, y María Eugenia Vázquez Semadeni de la UCLA. A esta última académica se debe una sensible y cuidadosa disertación sobre las valiosas contribuciones y aportes de Margaret Jacob a la historiografía y la academia, así como a fortalecer la divulgación de los estudios 
académicos sobre la historia de la masonería en el "mundo profano" y en la comunidad masónica. Fue, además, una oportunidad extraordinaria para ver juntos a dos "grandes" de la historiografía masónica, como son la profesora Jacob y el profesor Ferrer Benimeli. A pesar de su jubilación, Margaret Jacob continuará en su labor investigativa. Desde estas páginas, la $R E H M L A C+$ se une al homenaje de la comunidad académica para la profesora Jacob.

De la extensa agenda de eventos académicos de este año que abordarán el tema de la masonería, conviene distinguir dos de la mayor importancia que se preparan para el segundo semestre de 2018: el primero es la 2018 Quatuor Coronati Conference, bajo el tema "Los masones en el mundo trasatlántico", que se efectuará del 14 al 16 de septiembre en el George Washington Masonic National Memorial, en Alexandria, VA (Estados Unidos). El segundo gran evento será el $X V$ Symposium Internacional de Historia de la Masonería Española, bajo el tema general de "La masonería: mito e historia. En el III centenario de la fundación de la masonería moderna", a celebrarse en Lisboa, del 11 al 13 de octubre de 2018, organizado por el Centro de Estudios Históricos de la Masonería Española (CEHME), y con el patrocinio del Instituto Portugués de Estudos Maçónicos, el Centro Nacional de Cultura y la Associação Internacional de Estudos Ibero-Eslavos, y la coordinación científica de las universidades de Zaragoza, Sevilla, Lisboa y Aberta (CIDH). Esta será la segunda vez que el Symposium del CEHME se celebre fuera de las fronteras españolas y contará con la participación mayoritaria de investigadores de Europa y América.

Este número de la REHMLAC+ está dedicado prioritariamente a la publicación de una primera selección de los mejores estudios presentados en el IV Simposio Internacional de Historia de la Masonería y de los Movimientos Asociativos Latinoamericanos y Caribeños, celebrado en la Universidad de Costa Rica del 2 al 6 de noviembre del 2015 bajo el tema: "Prácticas asociativas y Modernidad, siglos XVIII-XXI", junto con otras contribuciones. Este encuentro reunió a más de 50 especialistas de España, Portugal, Cuba, Estados Unidos, Francia, Reino Unido, México, Ecuador, Venezuela, El Salvador, Colombia, Chile, Argentina, Brasil, Puerto Rico y Costa Rica, pertenecientes a más de 30 universidades y centros de investigación, dando continuidad así a los tres anteriores Simposios de corte latinoamericanista, celebrados en La Habana (2007, 2008) y la Ciudad de México (2010). Con el Simposio se conmemoró, además, los 150 años de la fundación de la masonería en Costa Rica (1865), el primer centenario de la Sociedad Teosófica en Costa Rica y el 75 aniversario de la Universidad de Costa Rica. Valor agregado a este Simposio es la firma de un "Convenio de Cooperación entre la Universidad de Costa Rica y la Gran Logia de Costa Rica", para el desarrollo de un programa académico que contribuya a la organización del 
fondo documental, bibliográfico y museístico de la Gran Logia, que favorezca la conservación y el uso académico de ese patrimonio.

La continuidad de estos simposios parece estar asegurada. La prueba es que el año pasado se celebró el V Simposio (La Habana, 2017), y el próximo se celebrará el VI Simposio en la ciudad de Zacatecas, bajo los auspicios de la universidad autónoma de ese nombre. Y es que los resultados y efectos de este tipo de eventos han sido fructíferos y cada vez involucran a un mayor número de personas que se dedican al estudio de la masonería y de los movimientos asociativos, especialmente en el continente americano, lo que se representa también en el número de actividades organizadas sobre esa temática o que la incluyen como parte de sus contenidos. El mejor ejemplo de esos frutos es la REHMLAC+, que nació durante el I Simposio (La Habana, 2007) como una revista académica y abierta de vocación latinoamericanista para la difusión y promoción de los estudios sobre la historia de la masonería, que operaría desde la Universidad de Costa Rica, y sería conducida por el "Grupo La Habana", así llamado por los investigadores que decidieron asumir esa tarea y desarrollar acciones eficaces y responsables para garantizar su existencia bajo un marco de estricta calidad académica y científica. En torno a la REHMLAC+ se han organizado seminarios, congresos, simposios, conversatorios, publicaciones y una larga serie de participaciones y contribuciones en el mundo académico, masónico y civil, con notable éxito. La REHMLAC+ sorprendió a masones y antimasones, pero también a historiadores, investigadores y académicos de las ciencias sociales, y a un extenso y heterogéneo público que por mucho tiempo estuvo limitado en su interés y búsqueda de información por las clásicas obras escritas por detractores y apologistas de la masonería. Además de la original vocación latinoamericanista, la REHMLAC ha ampliado su radio de acción divulgativa con investigaciones sobre la temática en un marco geográfico global, la $R E H M L A C+$, y dando cabida a estudios sobre otros movimientos asociativos. Con el tiempo, se ha unido a la REHMLAC+ un importante y valioso conjunto de colaboradores, académicos $\mathrm{e}$ investigadores, de decenas de geografías de América y Europa, cuyo trabajo ha sido altamente valorado por los índices y mecanismos de calificación de publicaciones académicas, como se revela en las evaluaciones y resultados obtenidos a lo largo de los años.

Sin embargo, los Simposios latinoamericanos y la $R E H M L A C+$ tienen una raíz más profunda. Buena parte de la actual historiografía latinoamericana sobre la masonería y otros movimientos asociativos, conocidos también como paramasonerías, tiene su origen en las primeras participaciones de latinoamericanos en los Symposiums Internacionales de Historia de la Masonería Española organizados desde 1983 por el CEHME, adscrito a la Universidad de Zaragoza, y bajo la tutela de su fundador y presidente de honor por largo tiempo José Antonio Ferrer Benimeli. Los primeros estudios del profesor Ferrer Benimeli 
sobre el tema surgieron en la década de 1970, en el eclipse de la dictadura franquista, y su publicación generó una nueva polémica desde los bandos masónicos, antimasónicos y académicos, pues su autor rompía con la tradicional "Historia de la Masonería" y generaba una nueva visión de la sociedad masónica desde la seriedad y la responsabilidad del académico, del historiador profesional y del científico social. Ferrer Benimeli revisó el pasado masónico y su contexto, puso en evidencia la naturaleza de las "grandes verdades de las historias oficiales y populares" de la masonería, explicó el origen de las leyendas y mitos, y abordó el contexto histórico de la masonería por medio del rigor científico y la objetividad, a través de la localización y el estudio de las fuentes documentales originales conocidas y desconocidas- en archivos y bibliotecas públicos, privados y "secretos", en las geografías europea y americana, sin olvidar que la visión sobre la masonería española debía ser explicada en el marco de la historia europea y americana, así como del desarrollo y transformaciones de las ideas, los sistemas políticos, las instituciones y la sociedad.

El valiente, solitario y arduo trabajo del profesor Ferrer Benimeli por varias décadas en el estudio de la temática masónica, encontró un punto de partida para generar una corriente historiográfica novedosa en España y Europa dentro de un revisionismo historiográfico y la crítica académica -en plena transición política española-, por medio de su participación en varias actividades, siendo el paso clave la organización de los simposios y de la fundación del CEHME en la Universidad de Zaragoza.

Poco a poco esta corriente se extendió por las universidades y centros de investigación, se interesó a los medios de comunicación social, a instituciones públicas y privadas, a la Iglesia católica y a la sociedad masónica, abriendo la puerta a nuevas generaciones de historiadores que estudiarán la masonería de frente, objetivamente y bajo principios científicos y académicos, abordando sin miedo la temática masónica asociada con otras muchas variables temáticas: las artes, la política, la mujer, el pacifismo, la guerra civil española y la represión posterior, los conflictos bélicos, los movimientos sociales y económicos, las biografías y las estructuras de poder, la Iglesia católica, el protestantismo, el judaísmo y el Islam, la colonización y el imperialismo, el esoterismo, la metodología y la historiografía, el racismo, la xenofobia, los movimientos segregacionistas e independentistas, el laicismo, la educación, la migración, la literatura, la prensa y los medios de comunicación, y un largo etcétera.

Los simposios del CEHME se convirtieron en el Aula Magna del CEHME, en una escuela de la historiografía sobre el fenómeno social masónico, donde cada dos o tres años se agrupaban decenas de investigadores venidos de varias partes del mundo y de todas las edades, para presentar los resultados de sus investigaciones y discutir académicamente sobre los temas convocados. El intercambio ha sido invaluable. 
Es así como con la experiencia de varios historiadores latinoamericanos en los simposios del CEHME, adquirida en años anteriores y copartícipes de la escuela de Ferrer Benimeli, se iniciaron los simposios latinoamericanos a partir del habanero de 2007, donde el diálogo entre historiadores de Europa y América se estrechó de tal modo, que hoy los lazos que los unen son indisolubles.

El presente número de la $R E H M L A C+$ es una muestra de la diversidad temática y procedencia de los artículos que se incluyen. Enmarcados en los siglos XIX y XX, los temas del laicismo, antilaicismo, comunismo, anticomunismo, ateísmo y confesionalidad, masonería y antimasonería, están presentes en las contribuciones de René Antonio Chanta, Dévrig Mollès e Ivonne Cortés. Por otra parte, José Antonio Ferrer Benimeli y Marco Novarino estudian la coyuntura política de la primera guerra mundial desde los marcos de la masonería española e italiana respectivamente, en el que la visión sobre los imperialismos del momento está presente. Ambos estudios son propicios para una mayor comprensión del fenómeno bélico desde una base social que posee una visión idealista sobre las relaciones humanas. Los movimientos migratorios y las redes de comunicación a través de la solidaridad, la sociabilidad y la institucionalidad masónica, son abordados por los interesantes trabajos de Roger Burt, Fernanda Cristina Santos, José Eduardo Franco, Valeria Aguiar Bobet, Eduardo Enríquez del Árbol y el ya citado Mollés, pasando por geografías tan diversas como Portugal, Brasil, Marruecos, España, Rumanía, Argentina, México, Estados Unidos y Gran Bretaña, entre otras. Estos trabajos ponen en evidencia la relevancia y particularidad de los vínculos masónicos en diversas circunstancias y el establecimiento de redes internacionales -transoceánica y transcontinental- de solidaridades y colaboración masónica. Enríquez del Árbol, además, da seguimiento al expansionismo masónico español en Estados Unidos y Canadá a finales del siglo XIX, que implicaba la extensión del rito primitivo y oriental de Memphis y Mizraím, una novedad en países con ritos existentes muy consolidados social y políticamente, hecho que la masonería española intentaría reproducir en varios países de América Latina a inicios del siglo XX. Dos estudios abordan los movimientos asociativos no masónicos, como son los de Leonardo Santamaría en cuanto a la cultura burguesa en Costa Rica a finales del siglo XIX a través de la formación de clubes sociales y asociaciones con intereses intelectuales y especulativos, y Otto Germán Mejía sobre la Sociedad Teosófica en El Salvador y varios países de América Latina entre 1929 y 1938, reconstruyendo la gira de Curuppumullage Jinarajandasa en este último año a través de las interconexiones de la teosofía con la política, la intelectualidad y la opinión pública, y las reacciones de la prensa y algunos sectores sociales ante las propuestas del masón y líder teosófico. Este estudio cobra mayor atractivo al asociarlo con el ya citado de René Antonio Chanta, pues ambos estudian la realidad salvadoreña en el mismo periodo. 
José Luis Romeu y Pablo Alejandro Suárez estudian la masonería del Caribe a finales del siglo XIX desde ángulos temáticos diferentes. El primero hace un análisis crítico de las interpretaciones de algunos historiadores españoles sobre la masonería autóctona de Cuba y Puerto Rico, confrontándolos con historiadores de estas geografías y su propia percepción de los integrantes y cuerpos masónicos de esa época. Suárez presenta un interesante estudio sobre la música masónica cubana finisecular, a través del rescate de valiosas fuentes originales e inéditas y de una propuesta metodológica para la gestión del patrimonio histórico musical de Cuba. Sylvia Hottinger entra nuevamente en el estudio de los "signos masónicos" en la fotografía, esta vez comparando fotografías publicadas en la red Internet que, en según las interpretaciones de quienes las utilizan, realizan ex profeso signos masónicos, con fotografías originales que estudia Hottinger valorando también el contexto en el que fueron tomadas y el lenguaje gestual y manual propio de las acciones que realizan los personajes. Los resultados son muy atractivos para conocer las "intenciones" de los autores de las citadas interpretaciones.

El objetivo de la REHMLAC+ para informar y divulgar los avances de la historiografía sobre la masonería y otros movimientos asociativos, se cumple en este número con las reseñas de nuevas publicaciones que realizan Ángel Guisado, Céline Sala, José Leonardo Ruiz y Antonio Morales. Estas se complementa con la entrevista a Ángel Guisado sobre su experiencia en el proceso de investigación de su tesis doctoral presentada en la Universidad de Cádiz en el 2017, con especial referencia a las cuestiones históricas más complejas de resolver en su trabajo, así como con la reseña elaborada por Fernando Anaya sobre el $I$ Seminario de investigación histórica "Dagli archivi alla ricerca. Confronto per una nuova stagione di studi sulla massoneria" (Centro Ricerche Storiche sulla Libera Muratoria, Turín, 2017). Estas contribuciones son de especial provecho para los investigadores nóveles y quienes se interesen por conocer la calidad del trabajo académico frente al empirismo, la interpretación antojadiza y la continuidad de las visiones apologistas y detractoras de la masonería. 


\section{Tabla de contenidos}

Equipo REHMLAC+ iii

Definición de la Revista... iv

\section{Presentación}

Prácticas asociativas y modernidad

Miguel Guzmán-Stein (Universidad de Costa Rica, Costa Rica).....

vi

Tabla de contenidos..................................................... xii

\section{Artículos}

"Wherever Dispersed" - The Travelling Mason in the Nineteenth Century

Roger Burt (Universidad de Exeter, Reino Unido).

El Club Internacional de San José y la cultura ilustrada finisecular Leonardo Santamaría Montero (Universidad de Costa Rica, Costa Rica).

Masonería y espacio público: El debate en torno a la "escuela atea" en Chile 1872 Ivonne Cortes Quintana (Universidad Autónoma de Chile, Chile).

Análisis de la visión de algunos europeos, sobre las masonerías autóctonas de Cuba y Puerto Rico, a finales del siglo XIX Jorge Luis Romeu (Universidad de Siracusa, Estados Unidos)

La inserción de una obediencia española en los Estados Unidos: el Soberano Consejo General Ibérico y la Gran Logia Simbólica Española (1892-1898)

Eduardo Enriquez del Árbol (Universidad de Granada, España)

La primera guerra mundial en el Boletín Oficial del Grande Oriente Español, 19141918

José Antonio Ferrer Benimeli (Universidad de Zaragoza, España). 
Imperialismo liberomuratorio? L'impatto della 'questione dalmata' sulla massoneria italiana (1914-1919)

Marco Novarino (Universidad de Turín, Italia)....

A Maçonaria no espaço insular atlântico português: As origens católicas da maçonaria madeirense

José Eduardo Franco (Universidad Abierta, Portugal) y Fernanda Santos (Universidad Federal de Amapá, Brasil)

Redes masónicas epistolares entre Marruecos, México y Cuba durante la segunda República española

Valeria Aguiar Bobet (Universidad Jaume I de Castellón, España)

Música para ritual masónico de Ramón Figueroa Morales: Documentos testimoniales sobre la práctica musical en la logia Prudencia no. 2 de Santiago de Cuba (1898-1928)

Pablo Alejandro Suárez Marrero (Universidad de Guanajuato, México)

Segunda gira del teósofo Jinarajadasa a América Latina, 1938. Análisis de sus conferencias y otros ensayos

Otto German Mejía Burgos, (Universidad Centroamericana “José Simeón Cañas”, El Salvador).......

Antilaicismo, anticomunismo y críticas a la masonería en la prensa católica salvadoreña durante el retorno del debate de la laicidad del Estado (1938-1940) René Antonio Chanta Martínez (Universidad Don Bosco, El Salvador).

Guerra fría, exilio y redes masónicas en América Latina: Notas preliminares en torno a la logia Soarele Romaniei (Buenos Aires, 1952-1958)

Dévrig Mollès (Universidad de Estrasburgo, Francia)

Las huellas del franquismo en el uso de los signos masónicos en Internet: Algunas fotografías de políticos de la segunda República española Sylvia Hottinger Craig (Universidad Carlos III de Madrid, España).

\section{Experiencias investigativas en Tesis}

Cayetano del Toro y Quartiellers: Biografía, obra y pensamiento (1842-1915) 


\section{Reseñas de actividades académicas}

I Seminario de investigación histórica "Dagli archivi alla ricerca. Confronto per una nuova stagione di studi sulla massoneria" (Centro Ricerche Storiche sulla Libera Muratoria, Turín, 2017)

Fernando Miguel Anaya-Gámez (Universidad de Málaga, España).

\section{Reseñas de publicaciones}

Liberalismo y masonería entre Europa y América. Diego Correa (1772-1843) de Manuel Hernández González

Ángel Guisado Cuellar (Universidad de Cádiz, España).

L'Amérique latine et la Caraïbe des Lumières : Une franc-maçonnerie d'influence de Alain de Keghel

Monarcas masones y otros príncipes de la Acacia de Javier Alvarado Planas

José Leonardo Ruiz Sánchez (Universidad de Sevilla, España)....

388

Simbolismo masónico. Historia, fuentes e iconografía de José Julio García Arranz Antonio Morales Benítez (Universidad de Cádiz, España). 